\title{
VELHOS OBJETOS X NOVOS OLHARES: OS USOS DO LIVRO DIDÁTICO NO ENSINO DE HISTÓRIA
}

\author{
Elaine Regina Mendes Lisbôa ${ }^{1}$ \\ Márcia Andrea Teixeira da Silva ${ }^{2}$ \\ Thalisse Ramos de Sousa ${ }^{3}$
}

\section{RESUMO}

O presente trabalho tem por objetivo refletir sobre os usos do livro didático no ensino de história, relacionando questões vivenciadas pelos professores, políticas voltadas para o livro didático, metodologias de ensino-aprendizagem, currículo oficial, ilustrações e novas tecnologias. Inicialmente o livro didático é abordado como um instrumento de reprodução de ideias e valores da cultura dominante, pontuando o papel do professor na construção e desconstrução de identidades e sujeitos. Em seguida, a relação poder e saber é questionada através de reflexões sobre as políticas públicas e o Programa Nacional do Livro Didático (PNLD). Adiante, destaca-se a importância de uma análise crítica da iconografia disponibilizada nesses materiais, em especial, às representações pejorativas presentes nas imagens relacionadas aos povos negros e indígenas. Por fim, trata-se da sobrevivência do livro didático mediante o surgimento de novas tecnologias, ressaltando a necessidade de novas metodologias, decorrentes de novos instrumentos. Temos, portanto o professor como responsável por estabelecer o diálogo entre o livro didático e as múltiplas questões do meio externo a fim de transformar alunos em cidadãos críticos e socialmente atuantes.

Palavras-chave: Livro didático; Ensino; História.

\section{OLD OBJECTS X NEW LOOKS: THE BOOK OF USES IN TEACHING HISTORY OF EDUCATION}

\begin{abstract}
This paper aims to reflect on the textbook uses in teaching history, relating issues experienced by teachers, policies to the textbook, teaching-learning methodologies , official curriculum, illustrations and new technologies. Initially the textbook is approached as a playback instrument of ideas and values of the dominant culture, scoring the teacher's role in the construction and deconstruction of identities and subject. Then the relationship power and knowledge is questioned through reflections on public policy and the National Textbook Program ( PNLD ). Soon after, highlights the importance of a critical analysis of the iconography available in these materials, in particular the present pejorative representations in images related to blacks and indigenous peoples. Finally, it is the survival of the textbook by the emergence of new technologies, highlighting the need for new methodologies, according to new instruments. We have therefore the teacher as responsible for establishing dialogue between the textbook and the multiple issues the external environment in order to transform students into critical and socially active citizens.
\end{abstract}

Keywords: Ledger didádico; Education; History. 


\section{INTRODUÇÃO}

Pensar o ensino de História, atualmente, é algo desafiador, visto que sua trajetória está permeada por manipulações, ideologias, silêncios e lacunas, enfim, elementos que moldam os discursos históricos, instigando o profissional da área a saberdesconstruir esses discursos utilizando-se do diálogo com os materiais disponíveis nas salas de aula.

$\mathrm{Na}$ contemporaneidade, emergem muitas discussões acerca do saber histórico escolar, direcionados para novas abordagens que dão vozes àqueles que por muitos séculos não possuíam espaço enquanto sujeitos históricos, e sim meros figurantes em um "palco" no qual apenas os "grandes homens" e os "grandes eventos" podiam se apresentar.

A partir dessa ideia, os Parâmetros Curriculares da Educação Nacional ampliam a noção de sujeito instigando os profissionais da educação a problematizarem "outras histórias" em sala de aula, proporcionando análise de desconstruções e reconstruções de sujeitos e objetos de pesquisa:

O sujeito histórico pode ser entendido, por sua vez, como sendo os agentes de ação social, que se tornam significativos para os estudos históricos escolhidos com fins didáticos, sendo eles indivíduos, grupos ou classes sociais. Podem ser assim todos aqueles que, localizados em contextos históricos, exprimem suas especificidades e características (...) Podem ser trabalhadores, patrões, escravos, reis, camponeses, políticos, prisioneiros, crianças, mulheres, religiosos, velhos, partidos políticos, etc. (BRASIL, 1997, p.29)

A partir dessas várias identidades, a escola precisa mudar, assim como os sujeitos que a compõem e seus recursos pedagógicos, buscando atingir osnovos anseios sociais. Tais transformações passaram a estabelecer intensos debates no campo educacional no que se refere ao currículo oficial, as metodologias de ensino e ao livro didático.

\section{LIVRO DIDÁTICO E ENSINO DE HISTÓRIA}

Nesse contexto, o livro didático, numa perspectiva tradicional, passou a ser questionado, sendo objeto de discussão de historiadores, pedagogos, entre outros estudiosos da educação, que passam a analisá-lo em um sentido mais amplo, percebendo as relações sociais, culturais, econômicas, históricas e pedagógicas que envolvem os conhecimentos que entrelaçam tal publicação. Assim reforça Choppin"Os livros didáticos não são apenas instrumentos pedagógicos: são também produtos de grupos sociais que procuram, por intermédio deles, perpetuar suas identidades, seus valores, suas tradições suas culturas"(CHOPPIN apud BITTENCOURT, 2004, p. 69)

Por isso, o livro didático configura-se, ainda hoje, enquanto o principal material pedagógico no processo de ensino-aprendizagem. Trata-se do objeto cultural marcante que integra a "tradição escolar" de professores e alunos, estabelecendo uma posição privilegiada há pelo menos dois séculos no ambiente escolar.

Quando se trata do livro didático de História, os não ditos e a verdade absoluta possuem intenções direcionadas para interesses de grupos, por isso, historicamente é utilizado como instrumento de controle de ensino por parte de diversos agentes do poder. 
Neste sentido, busca-se entendê-lo como tal, sugerindo situações que questionam "os usos" dos manuais, tornando as aulas de histórias mais críticas e reflexivas e retirandoas da condição de meros espaços de reprodução, pautadas na memorização das datas e fatos, tendo como recursos o quadro, o livro didático, muitas vezes, numa perspectiva apenas narrativa, e a figura do docente, não raramente, reprodutor de idéias cristalizadas.

Segundo Bittencourt (2005, p. 73) o "papel do livro didático na vida escolar pode ser o de instrumento de reprodução de ideologias e do saber oficial imposto por determinados setores do poder e do estado", dessa forma, o processo histórico-cultural, o cotidiano e as experiências dos segmentos subalternos da sociedade podem ser omitidos e/ou distorcidos, influenciando o fazer pedagógico de muitos docentes.

Nessa perspectiva, os textos e imagens nos livros didáticos de História, estão carregados de preconceitos e racismos acerca dos índios e escravos, os quais sempre são mostrados como subalternos e preguiçosos,limitando as suas análises aos processos de exploração e submissão, omitindo qualquer possibilidade desses grupos étnicos expressarem a sua cultura.

Assim,visualizam-se construções de estereótipos que funcionam como representações pautadas na forma como um dado grupo apreende o mundo social, convergindo em discursos intencionais, envolvendo práticas e apropriações, contextos de um contorno social. Diante disso, essas representações são construídas de acordo com a apreensão do mundo, não revelando dessa forma, discursos neutros, são carregados de intencionalidades impostas por um determinado grupo.Portanto:

As representações do mundo social, assim construídas, embora aspirem à universalidade de um diagnóstico fundado na razão, são sempre determinadas pelos interesses de grupo que as forjam. Daí, para cada caso, o necessário relacionamento dos discursos proferidos com a posição de quem os utiliza. (CHARTIER, 1990, p.17).

$\mathrm{Na}$ escola não foi diferente, por mais que historicamente tenha sido elaborada, do ponto de vista institucional, como um ambiente ideologicamente construído para a experimentação de processos de ensino e aprendizagem, outros espaços quebraram a sua redoma, expondo-a num universo de informações que a sociedade passou a exigir, muitas vezes inconscientemente, que fosse trabalhada na escola.

A partir desse entendimento, a cultua escolar e a cultura dos sujeitos envolvidos deve ser problematizada, uma vez que alunos, professores e demais atores educacionais fazem parte da dinâmica social, portanto, as suas relações fora do espaço escolar de alguma forma influenciam a dinâmica da instituição. Neste sentido, Edimilson Pereira comenta:

(...) de um lado, a escola oficial estabelece programas de ações universalizantes, entrando em choque com os anseios de grupos locais, que reivindicam o atendimento de suas demandas particulares(...) Nesse sentido, é interessante uma aproximação aos procedimentos adotados pelos vários agentes que participam dos processos de ensinoaprendizagem em diferentes contextos. (PEREIRA, 2003, p.14-21)

Dessa forma, a diversidade cultural surge enquanto saber escolar, trazendo para as aulas de História as discussões acerca da realidade dos sujeitos educacionais, objetivando assim, elementos significativos que proporcionem interesse e sentido no processo de 
ensino-aprendizagem. Através dessa nova perspectiva passou-se a questionar os métodos de ensino, como se evidencia nos Parâmetros Curriculares Nacionais:

Os métodos tradicionais de ensino - memorização e reprodução passaram a ser questionados com maior ênfase. Os livros didáticos difundidos amplamente e enraizados nas práticas escolares foram criticados nos conteúdos e nos exercícios propostos. A simplificação dos textos, os conteúdos carregados de ideologias, os testes, os exercícios sem exigências de nenhum raciocínio foram apontados como comprometedores de qualquer avanço no campo curricular formal. (BRASIL, 2007, p. 28).

Portanto, instigados por esse novo direcionamento do Ministério da Educação e dos anseios da nova sociedade, o livro didático está passando por um processo de mudança, vale ressaltar que tais rupturas são lentas e graduais, tendo em vista que ainda existem setores resistentes a essas transformações, assim como adequações e avanços das políticas públicas de formação de professores e do Programa Nacional do Livro Didático.

\section{LIVRO DIDÁTICO E AS POLÍTICAS PÚBLICAS NO BRASIL}

O livro didático continua sendo o principal instrumento de trabalho e produto cultural que a maioria dos professores e alunos tem acesso, funcionando como suporte fundamental na relação de ensino-aprendizagem. No entanto, muitos professores veem os materiais didáticos como meios de divulgações de determinadas concepções e ideologias, como meramente conteudistas, não se preocupando com seu verdadeiro objetivo de mediador do processo de aquisição de conhecimento.

No entanto, para entendermos o porquê deste material ser tão amplamente utilizado devemos remeter às políticas públicas adotadas no Brasil, estas nada mais são do que programas, projetos ou ações pensadas e implementadas pelo Estado, com a participação de entes públicos ou privados, que visam assegurar determinado direito de cidadania, de forma difusa ou para determinado seguimento social, cultural, étnico ou econômico. Tais políticas se difundiram mais amplamente nas décadas de 90 , principalmente no que se refere à educação, mas inicia-se nos anos 60 e 70.

O Estado brasileiro, a partir destas décadasvolta-se para a educação ampliando o número de vagas na rede escolar e consequentemente há um impulso na indústria cultural, com incentivos financeiros, fiscais, tecnológicos, além de isenção nas importações de maquinários para a indústria editorial, trazendo enormes benefícios financeiros ao setor industrial em consonância com os ideais de segurança nacional. O uso do livro didático foi expandindo, devido ao crescente apoio do Estado à indústria editorial tornando-se o maior comprador e distribuidor.

A partir desse período, o Estado impulsionou a indústria cultural vinculando-a diretamenteao processo de democratização, ampliação ou massificação do ensino. Analisando o conteúdo, os objetivos e a fundamentação teórico-metodológica dos currículos de história, constatamos que os novos programas curriculares elaborados e implementados na década de 1970 se corporificaram no livro didático. Houve uma adoção em massa de livros didáticos, incentivado pelo Estado e pela indústria editorial brasileira, em plena expansão, por meio dos incentivos estatais. $\mathrm{O}$ livro didático assumiu assim, a forma do currículo e do saber nas escolas. (FONSECA, 2008, p.50) 
Com o fim do período militar e democratização do Brasil na década de 80, inicia-se uma ampla renovação dos saberes históricos relacionando as pesquisas acadêmicas e a indústria editorial. Foram propostas mudanças na linguagem e na forma de apresentação no entanto, a produção e a venda em massa permaneceram intocáveis e o maior financiador continuava sendo o Estado brasileiro.

A partir de 1985 com o decreto federal 91.542, as políticas públicas do Governo Federal instituíram o Programa Nacional do Livro Didático (PNLD) e sua política de execução é feita pelo Fundo Nacional de Desenvolvimento da Educação (FNDE), este programa instituiu mudanças relevantes e substanciais ao antigo programa do livro didático, estabelecendo como meta o atendimento a todos os alunos de primeira a oitava série do primeiro grau das escolas públicas federais, estaduais, territoriais, municipais e comunitárias do país, com prioridade para os componentes básicos: Comunicação e Expressão e Matemática.

O PNLD propôs ainda, indicação do livro didático pelos professore; reutilização do livro, implicando a abolição do livro descartável e o aperfeiçoamento das especificações técnicas para sua produção, visando maior durabilidade e possibilitando a implantação de bancos de livros didáticos; extensão da oferta aos alunos de $1^{\mathrm{a}}$ e $2^{\mathrm{a}}$ série das escolas públicas e comunitárias; fim da participação financeira dos estados, passando o controle do processo decisório para a FAE e distribuição gratuita às escolas públicas.

Em março de 1990, o Brasil participou da Conferência Mundial sobre Educação paraTodos, realizada em Jomthien, na Tailândia, e recebeu como uma das tarefas, construir o Plano Decenal de Educação para Todos (1993-2003). E uma questão que mereceu destaque foi o livro didático, por ser considerado um dos maiores insumos da instituição escolar, formularam-se estratégias para um melhor aproveitamento no processo de ensinoaprendizagem:

Uma nova política do livro começa a ser formulada, a partir da definição de padrões básicos de aprendizagem que devem ser alcançados na educação fundamental. Além dos aspectos físicos do livro, passarão a ser asseguradas a qualidade do seu conteúdo (fundamentação psicopedagógica, atualidade da informação em face do avanço do conhecimento na área, adequação ao destinatário, elementos ideológicos implícitos e explícitos) e sua capacidade de ajustamento a diferentes estratégias de ensinoadotadas pelos professores. (BRASIL, 1993, p.25)

Com estas novas propostas efetuadas, principalmentepelos incentivos externos, financiadores como o Banco Mundial, FMI - Fundo Monetário Internacional e CEPALComisión Económica para América Latina y El Caribe, passaram a estabelecer as diretrizes para a elaboração das políticas públicas brasileiras, exigindo que fosse realizado o Plano Decenal de Educação para Todos (1993-2013),onde uma nova política para o livro didático começava a ser formada baseada em determinados padrões de aprendizagem.

A partir de 1994, conforme algumas mudanças baseadas no Plano Decenal, iniciase um processo de avaliação dos livros didáticos. Neste sentido, a Secretaria de Educação Básica (SEB) passou a coordenar o processode avaliação pedagógica sistemática das obras inscritas pelas editoras no PNLD. Esse processo é realizado em parceria com universidades públicas que se responsabilizam pela avaliação de livros didáticos nas seguintes áreas: alfabetização, língua portuguesa, matemática, ciências, história e geografia. (BRASIL, 2007) 
A produção dos livros deve estar de acordo com as regras impostas pelo governo, caso contrário, os livros são excluídos do PNLD. Depois do processo de escolha nas escolas, o governo compra os livros das editoras. O gasto é alto, existe uma burocracia e as editoras e o governo esforçam-se por defender seus interesses para produzir e colocar nas escolas um material com custos reduzidos. Esse processo de avaliação foi aprimorado pelo Ministério da Educação e algumas medidas já começaram a surtir efeito como a publicação do guia que classifica as obras de acordo com a avaliação dos especialistas.

Com a extinção, em fevereiro de 1997, da Fundação de Assistência ao Estudante (FAE), a responsabilidade pela política de execução do PNLD é transferida integralmente para o Fundo Nacional de Desenvolvimento da Educação (FNDE). O programa é ampliado tanto no que se refere às disciplinas quanto aos níveis envolvidos, expandindo para o Ensino Médio e Jovens e Adultos.

Neste sentido, o PNLD vem se ampliando a cada ano sendo caracterizado como uma política compensatória, enquanto se apresenta como um instrumento capaz de levar aos estudantes das classes populares novas aprendizagens, haja vista que em sua maioria estes não tem acesso a outra atividade sociocultural.

Nesta perspectiva, segundo o FNDE, se gasta milhões na compra de livros didáticos, porém ainda é possível verificar que ocorre falta de livros nas escolas, em sentido qualitativo e quantitativo. Vale lembrar que o livro didático é um material de aprendizagem dos estudantes e não uma mercadoria como muitas vezes é tratado.

Ao mesmo tempo em que ocorrem avanços na política de execução do livro didático, como a avaliação e a elaboração do guia dos livros, observa-se que o controle para realizar esta avaliação é do Governo Federal, já que os professores realizam uma pseudo-escolha e que os conhecimentos, a difusão da cultura que são abordados nas escolas e que adentram os lares dos estudantes podem ser sugeridos via este material didático. Neste sentido, a questão está diretamente relacionada aos conteúdos abordados no livros, já que o livro didático também pode ser considerado difusor de cultura, o governo "precisa" direcionar a cultura a ser transmitida aos estudantes/comunidades nas escolas públicas de todo o país.

As críticas em relação aos livros didáticos, como afirma Bittencourt (2011, p. 67), apontam para muitas de suas deficiências de conteúdo, suas lacunas e erros conceituais e informativos. No entanto, o problema de tais análises reside na concepção de que seja possível existir um livro didático ideal, uma obra capaz de solucionar todos os problemas do ensino, um substituto do trabalho do professor. Para a referida autora, esse recurso possui limites, vantagens e desvantagens como os demais materiais dessa natureza e é nesse sentido que precisa ser avaliado.

Para Fonseca (200, p. 54), a saída para todos os entraves do livro didático recai no papel do professor, onde requer uma revisão das formas de seu uso. Assim, sugere que se complemente o referido material e diversifique as fontes historiográficas, ponderando-o como uma fonte importante, mas não a única.

O ensino de história é um espaço complexo, no qual atuam diferentes propostas de saber e poder, cabendo aos professores de história o papel fundamental de desenvolver um ensino que contribua para a formação do pensamento crítico e reflexivo, para a construção da cidadania e para a consolidação da democracia entre nós... O exercício da crítica é nossa principal ferramenta nas lutas cotidianas pela (re)construção da história. (FONSECA, 2008, p.56). 


\section{A RELAÇÃO ENTRE TEXTOS E IMAGENS NOS LIVROS DIDÁTICOS}

Ao longo do tempo as fotos, gravuras, filmes e ilustrações têm sido utilizados enquanto recurso pedagógico. Em meados do século XIX os livros didáticos já possuíam ilustrações de cenas históricas intercaladas nos textos. Desde esse período o livro didático é considerado como principal ferramenta ou instrumento de trabalho.

Existe uma grande preocupação dos pesquisadores franceses em relação às ilustrações nos livros didáticos de história. Dentre as pesquisas, dois pontos necessitam de maior atenção; o primeiro refere-se aos trabalhos dos manuais escolares do século XX, as pesquisas tentam recuperar o acervo iconográfico que se configurou a memória histórica enfatizando aspectos ideológicos das ilustrações que evidenciam a galeria de heróis representados nos livros didáticos. O outro ponto a ser destacado é relativo à evolução das técnicas gráficas, as imagens que nos livros didáticos fazem concorrência com os textos escritos.

A historiadora Circe Bittencourt (2003, p. 80), destaca o importante trabalho dos historiadores franceses que dedicam grande importância às imagens e ilustrações nos livros didáticos. Destaca-se que nesses estudos as crianças fazem uma fácil relação das imagens com os textos, viabilizando um avanço na compreensão histórica. A estratégia da dualidade de imagens e textos possibilita o desenvolvimento da inteligência da criança e sua relação com a memória.

No Brasil, desde o século XIX é possível observar o avanço das ilustrações nos livros didáticos a partir da escolarização pública até a atualidade. O livro didático torna-se um importante divulgador das obras plásticas produzidas no século XIX, como o 7 de Setembro de Pedro Américo e a Primeira Missa no Brasil, de Victor Meireles de Lima.

Houve ainda grande preocupação em pesquisar possíveis retratos de personagens da vida administrativa do país desde a fase colonial, Tomé de Sousa e Pedro Álvares Cabral são exemplo disso. A história política representa ilustrações dos chefes políticos, reis e presidentes constituindo uma iconografia ilustre e aristocrática.

Os imperadores do Brasil são representados em um evidente paradoxo, Dom Pedro I morreu aos 34 anos, jovem, portanto é representado como pai jovem do filho velho, Dom Pedro II que com apenas 15 anos se torna chefe de estado, aparece nos livros didáticos bem idoso. Tal paradoxo fomentado pela interpretação republicana de que a monarquia seria um regime político envelhecido.

Em relação aos presidentes da república, a figura de Getúlio Vargas é a mais recorrente, sobretudo quando se refere à Revolução de 1930. Diante de tal evidência, levantamentos com cerca de 300 alunos de escolas da cidade de São Paulo em 1995 demonstra que $87 \%$ dos alunos ao serem apresentados a imagens de vários presidentes, só reconheciam Getúlio Vargas e desconheciam inclusive a figura de Juscelino Kubitschek.

Enquanto inovação nas representações dos chefes políticos é possível observar a substituição dos retratos em preto e branco e em obras mais recentes se verifica charges retiradas de jornais e também produzidas por cartunistas.

De um modo geral, no Brasil não existem muitas pesquisas direcionadas a produção iconográfica na área de história, no entanto, alguns trabalhos visam analisar como certos elementos sociais são representados, sobretudo os indígenas e a população negra. 
Alguns estudos revelam que os livros didáticos do ensino de história reforçam uma omissão de elementos da vida do povo negro, ou seja, aspectos de categoria social e elementos culturais são apresentados, costumeiramente, apenas numa dimensão folclórica. Além disso, é necessário superar a dicotomia de submissão e opressão, problematizando a questão da resistência dos negros, em consonância com esse entendimento a Lei 10.639/03 trata da obrigatoriedade do ensino de história e cultura africana e afro-brasileira nas escolas do Ensino Fundamental e Médio, criando um desafio para o mercado editorial.

Assim, deve-se promover questionamentos acerca das imagens depreciativas dos negros e como esse sujeito é representado nos livros didáticos onde se enfatiza o processo de escravidão desde o continente africano e ainda se evidencia a violência e a crueldade a que esse povo foi submetido durante o período colonial. (SILVA, 2011, p. 10)

Problematiza-se que os livros didáticos escolhem imagens que contribuem para uma não aceitação e não identificação dos alunos negros com seus antepassados, uma vez que as ilustrações representam o negro em contextos de sofrimento, violência e coação.

As representações dos povos indígenas nos livros didáticos de história do Brasil despertaram diversos questionamentos em relação às interpretações dos povos indígenas no processo do ensino de história e ainda a respeito dos métodos que viabilizam uma articulação entre imagem e texto, o que requer uma leitura atenta acerca das ilustrações produzidas para o uso pedagógico. É possível perceber uma variação metodológica significativa em que pese às permanências e rupturas na maneira de discutir de que maneira os povos indígenas são representados nos livros didáticos.

Circe Bittencourt (2005, p. 81) destaca dois livros didáticos de história do ensino primário mais conhecidos, com suas primeiras edições nos anos 70 e 80 do século XIX, escritos por autores religiosos, o cônego Fernando e Joaquim Maria de Lacerda. Este último viveu na França e sua pesquisa sobre os povos indígenas foi realizada a partir de obras de viajantes franceses. Essas primeiras obras representavam o indígena como selvagem, na grande maioria das ilustrações destacava-se os rituais antropofágicos e as guerras. (BITTENCOURT, 2005, p. 82).

Essas produções reverenciam bastante o papel dos religiosos na obra missionária e civilizatória a partir do trabalho da catequese. Os indígenas são representados no processo de constituição da história escolar em vários desses exemplares em cenas da representação da morte do primeiro bispo do Brasil em rituais antropofágicos, denota-se aí uma demarcação do povo indígena enquanto selvagem por esses autores.

Em 1900, João Ribeiro representa os povos indígenas de outra maneira em seu livro História do Brasil das escolas primárias. Este antropólogo pernambucano de influência alemã destaca os conflitos originados entre brancos e indígenas e ainda aborda as especificidades da cultura desse povo, dessa forma é possível afirmar as mudanças observadas em relação à representação do indígena no livro didático. João Ribeiro apresenta em sua obra ilustrações como a figura do Índio Uapédo Amazonas e ainda $\mathrm{O}$ Último Tamoio, esta última reproduzida na obra de Rodolfo Amoedo, de 1883.

Em 1916, Afrânio Peixoto, seguidor dos ideais racistas de Nina Rodrigues expõe na obra Minha Terra e Minha Gente uma concepção da necessidade de embranquecimento da população brasileira. Nesta obra, o índio segue como o selvagem responsável pela preguiça e mestiçagem do povo brasileiro.

Circe Bittencourt (2005, p. 83) acompanha a literatura didática no que tange as ilustrações do indígena e pontua alguns questionamentos acerca das várias versões do 
indígena nos livros de ensino de história: "as ilustrações ampliam as informações dos textos? A permanência nas obras atuais de ilustrações escolhidas ainda no século XIX indicam igualmente a continuidade das interpretações?" (BITTENCOURT, 2005, p. 84).

Os questionamentos da autora norteiam uma reflexão acerca de como as representações do indígena são demarcadas nos livros didáticos ao longo do tempo. É necessário que o docente se posicione de maneira crítica em relação à literatura didática, isso implica também para as demonstrações iconográficas apontadas nos mesmos, para que haja uma abordagem mais reflexiva junto aos alunos.

É importante, portanto, que o aluno observe que os povos indígenas são mencionados nos livros didáticos em poucos momentos do processo histórico da sociedade brasileira. Observa-se isso no início da colonização, na fase de conquista do território europeu para justificativa de inserção de escravos africanos e em fase mais contemporânea, em temas ligados a demarcação de terra.

Em linhas gerais, o professor enquanto mediador do livro didático deve estabelecer a importância dessa ferramenta cultural em seus vários aspectos; nos conteúdos e nas ilustrações, que devem ser passíveis a análises e reflexões.

"Fazer os alunos refletirem sobre as imagens que lhes são postas diante dos olhos é uma das tarefas urgentes da escola e cabe ao professor criar oportunidades, em todas as circunstâncias, sem esperar a socialização de suportes tecnológicos mais sofisticados para diferentes escolas e condições de trabalho que enfrenta, considerando a manutenção das enormes diferenças sociais, culturais e econômicas pela política vigente." (BITTENCOURT, 2005, p. 89).

\section{LIVROS DIDÁTICOS E NOVAS TECNOLOGIAS}

Muito se fala em relação ao livro didático, sabemos que apesar das novas tecnologias ele continua sendo o material didático referencial para alunos e professores, apesar do preço e das críticas, todos os anos uma infinidade de obras são lançadas no mercado nacional, movimentando vultosas cifras.

Os estudos e pesquisas voltam-se para uma grande questão: "O livro didático sobreviverá às novas tecnologias?" Para tal discussão é necessário analisar a constituição histórica do livro e da escola. Segundo Ken Morrison (1995, p.34), o livro nada mais é que o suporte material usado pela escrita, desde as antigas lápides de pedras, passando pelos papiros manuscritos até chegar na versão impressa industrialmente. A mudança no formato também implicou na mudança de finalidade, se antes o livro era portador de segredos manipulados por poucos, a exemplo da bíblia, após a possibilidade de reprodução em massa, este virou instrumento de divulgação dos saberes.

A materialidade do livro é versátil, sendo hora papel e tinta, hora sulcos de argila sobre pele animal ou pixels numa tela de computador, portanto não faz sentido o prenúncio que o livro didático será extinto por conta de novos suportes tecnológicos, muitas hipóteses podem ser consideradas nesta situação (Munakata, 1997). Lembrando que historicamente alguns confrontos interessantes entre as artes acharam simbiose, como por exemplo, pintura e fotografia, teatro e cinema, cinema e televisão, assim considerando o livro numa 
perspectiva literária, ele também pode se afirmar enquanto arte. Sobre isso Regina Zilberman(2001 p. 119) autora do livro "Fim do Livro, Fim dos leitores?" fala:

Livro e literatura constituem, por força da índole da escrita e da materialidade do papel, as duas faces de uma única moeda. A expansão do primeiro garantiu a ascensão da segunda, que, até a invenção da imprensa, circulava entre grupos seletos e aristocráticos; ou então se sustentava graças à circulação oral, efêmera por natureza (...) A sobrevida do livro é a da literatura, no modo conforme se apresenta em nossos dias. Porque suscita a interferência do leitor, este também não a abandona. (ZILBERMAN, 2001 p. 119)

Roger Chartier (1998, p.12), quando indagado se "o livro em papel está em perigo" responde que livros de história, ensaios filosóficos, vão permanecer na forma normal de circulação, enquanto as enciclopédias e os dicionários tendem a seguir a forma eletrônica. $\mathrm{O}$ estudioso adverte que novas materialidades do livro podem implicar em novas formas de leitura.

O fluxo sequencial do texto na tela, a continuidade que lhe é dada, o fato de que suas fronteiras não são mais tão radicalmente visíveis, como no livro que encerra, no interior de sua encadernação ou de sua capa, o texto que ele carrega, a possibilidade para o leitor de embaralhar, de entrecruzar, de reunir textos que são inscritos na mesma memória eletrônica: todos esses traços indicam que a revolução do livro eletrônico é uma revolução nas estruturas do suporte material do escrito assim como nas maneiras de ler. (CHARTIER1998, p.12-13)

Percebe-se que não existe obra independente do suporte material que viabiliza sua chegada ao leitor, em outras palavras o livro eletrônico continua sendo livro, embora em cada momento tenha uma materialidade peculiar à sua época. A mesma ideia aplica-se ao livro didático, que embora num outro formato continua sendo usado em sala de aula com o mesmo propósito, servindo a mesma concepção de escola vigente no Brasil até os dias atuais. A prática escolar num local e tempo específico para esta atividade é um grande esforço para construção de um corpus de conhecimentos escrituráveis, com conteúdos selecionados e que fazem sentido. Estudar na escola é ler os livros e materiais didáticos que os professores selecionam.

Vicente (1994, p.56) nos coloca o livro didático como elemento estruturante da concepção atual de escola, baseada na transmissão do conhecimento, repetição, progressão, daí a garantia de sua sobrevivência. Se a escola está em crise, o formato de aprendizagem continua legitimado e, o livro, por sua vez, reafirma-se, mesmo que num novo suporte material, mas seu propósito se mantém, isso perpassa principalmente pela aprendizagem da língua. A escola é o local para obtenção de conhecimentos formais, onde se aprende a ler e escrever. O livro ainda é o portal de apresentação a esse mundo letrado e da cultura escrita dominante na maior parte das sociedades atuais, sendo uma importante ferramenta na preparação para codificação do mundo por parte dos alunos.

Com o advento da internet percebemos novas relações no contexto ensinoaprendizagem e apropriação do conhecimento. O conhecimento do livro é respaldado pela autoria, que muitas vezes é sinônimo de pesquisa, responsabilidade, confiabilidade e respeito. Já o conhecimento virtual subverte a lógica dessa relação de poder hierárquica, através da autoria descomprometida. Todos podem ser autores, basta fazer uso dos 
inúmeros espaços disponíveis, tais como, fóruns, blogs, sites, enciclopédias virtuais e etc. Zilberman complementa:

As mudanças decorrentes dos novos instrumentos de computação e multimídia afetam profundamente o processo de produção escrita e de leitura, que se torna, de um lado, mais solitário e menos dialógico, porque resulta da relação do sujeito com a máquina, de outro, porém, apresentase alternativas técnicas de manipulação colocadas ao alcance do recebedor, o usuário do mecanismo, a quem se faculta intervir no texto, driblando a proibição imposta pela noção de propriedade intelectual. (ZILBERMAN, 2001, p. 115-116)

As relações entre o livro didático e as novas tecnologias podem resultar em saldos bem positivos. É necessário transitar pelas diversidades dos códigos. Roger Chartier (2002, p.23) analisa que as leituras atuais são fragmentadas, não permitindo a percepção do caráter singular da obra, considerando fragmentos de textos, capítulos de livros, sites de certos assuntos, temas pontuais. O professor é o mediador capaz de dar sentido a essas descontinuidades.

Novas tecnologias implicam em novas relações. São múltiplas linguagens para dialogar. Os livros trazem sites como referências bibliográficas, indicam links para consulta, alguns cursos de inglês e faculdades fazem provas em plataformas virtuais, têm lousas digitais, livros são acompanhados de CD-ROM com imagens ou áudios, ebooks e audiobooks são cada vez mais vendidos e o professor que não dialoga com tais códigos, não dialoga com os alunos. É necessário fazer a ponte entre a tecnologia e a aprendizagem, despertando para as novas formas de aprender e conviver com o conhecimento. Tratandose de tecnologias ressalta-se a preocupação em evitar a exclusão, chamada por Roger Chartier, de "iletrismo".

De outro lado, a revolução eletrônica, que parece repentinamente universal, pode também aprofundar, e não reduzir, as desigualdades. É grande o risco de um novo "iletrismo", definido não mais pela incapacidade de ler e escrever, mas pela impossibilidade de aceder às novas formas de transmissão do escrito. (CHARTIER, 2002, p.112)

As novas tecnologias são elencadas como elementos essenciais a serem considerados na escola, uma vez que de maneira geral, os alunos são nativos digitais e, mesmo com condição social menos privilegiada, são contemporâneos deste mundo tecnológico e globalizado e boa parte deles já usa as novas tecnologias de modo recorrente.

Nesse contexto, há investimento pesado das editoras, já que nenhuma delas quer ficar de fora da compra governamental brasileira. Nos últimos editais do PNLD, já são pressupostos recursos que consideram a cultura digital junto aos livros impressos. No conteúdo dos próprios livros didáticos, as novas tecnologias já são tematizadas - a produção de email e blog, por exemplo, são temas recorrentes nos livros didáticos, bem como nas indicações de bibliografia.

O governo brasileiro realiza a compra dos livros didáticos que atendam a uma série de critérios de qualidade (pedagógica e técnica) instituída anualmente em editais. $\mathrm{Na}$ instância pedagógica, quem avalia essa "qualidade" são comissões de técnicos vinculadas a diferentes universidades no país (varia conforme a disciplina analisada) que aprovam ou reprovam os livros a serem comprados pelo governo. Atualmente, há programas de compra 
de livros governamentais com suas respectivas normatizações, em que se consideram as especificidades do material a ser comprado para os diferentes níveis de ensino.

Nessas avaliações, há critérios gerais e específicos para as coleções de livros de cada disciplina. O livro didático, na sua versão digital também apresenta as mesmas características do material impresso: textos para leitura, espaços de consulta, imagens e propostas de atividades. No entanto, ele é muito mais que isso. Sua principal característica é a possibilidade da interação permanente do leitor-navegador com o texto e com todos os demais dados e recursos disponíveis na rede digital. Ler na tela de um computador não é a mesma coisa que ler um livro impresso. Com o livro eletrônico eu posso navegar inteiramente por todo o texto. Realizar todos os tipos de relações, cruzamento de informações e comparações em um tempo mínimo.

\section{CONSIDERAÇÕES FINAIS}

O livro didático foi configurado historicamente, enquanto o único instrumento pedagógico do professor, transformando-o, muitas vezes, em um "refém" de suas armadilhas. Em se tratando da disciplina de História, este se apresentava como um manual de datas e fatos dos "heróis nacionais".

Nesse sentido, é necessário que o docente desenvolva o seu olhar crítico diante dos silêncios, dos não ditos e intenções múltiplas das narrativas históricas, por meio de formações iniciais/continuadas, assim como das experiências e leituras de mundo que permeiam os sujeitos educacionais no seu cotidiano.

A partir dessa ideia, os livros didáticos devem acompanhar as transformações sociais. É nessa perspectiva que os seus usos variam, um exemplo é o livro digital, visto que ganha espaço no mundo contemporâneo. Com essas inovações, os velhos objetos poderão ser ressignificados permitindo novos olhares e outras histórias em sala de aula.

\section{REFERÊNCIAS}

BITTENCOURT, Circe Maria Fernandes. Ensino de Historia: fundamentos e métodos. São Paulo: Cortez, 2004.

. O Saber Histórico em sala de aula. São Paulo: Contexto, 2005.

BRASIL, Secretária de Educação Fundamental. Parâmetros Curriculares Nacionais:História e Geografia. Brasília: DF, 1997.

, Secretaria de Educação Básica. Plano Decenal de Educação para Todos. Brasília: MEC, 1993.

Secretaria de Educação Básica. Programa de Formação Continuada de Professores dos Anos/Séries Iniciais do Ensino Fundamental: Alfabetização e Linguagem.11228Secretaria de Educação Básica. Brasília: Ministério da Educação, Secretaria de EducaçãoBásica, 2007. 
CASSIANO, CéliaCristina de Figueiredo. O Mercado do Livro Didático no Brasil: da criação do Programa Nacional do Livro Didático (PNLD) à entrada do capital internacional espanhol (1985-2007). 252 p. Tese. Puc. São Paulo, 2007.

CHARTIER, Roger. Textos, Impressos, Leituras. In:A história cultural: entre práticas e representações. Lisboa: Diefel, 1990.

. A aventura do livro. Do leitor ao navegador. São Paulo: UNESP, 2002.

. Os desafios da escrita. São Paulo: UNESP, 2002.

FONSECA, Selva Guimarães. Didática e prática de ensino de história. $7^{\mathrm{a}}$ ed. CampinasSP: Papirus, 2008.

MACIEL, Francisca Isabel Pereira. Novas Tecnologias x Livros didáticos: por uma didática da invenção. In: Coleção Didática e Prática de Ensino. SANTOS, Lucíola (Orgs.). Belo Horizonte: Autêntica, 2010.

MORRISON, Ken e outros. Cultura, pensamento e escrita. São Paulo: Ática, 1995.

MUN, kazumi. Livro, livro didático e forma escolar. In: Coleção Didática e Prática de Ensino. SANTOS, Lucíola (Orgs.). Belo Horizonte: Autêntica, 2010.

PEREIRA, Edimilson de Almeida. Educação em festas populares. In: Revista Presença Pedagógica. Belo Horizonte, n.51. mai/jun.2003.ZILBERMAN, Regina. Fim do Livro? Fim do Leitor?. São Paulo. Senac, 2001.

\footnotetext{
1 Aluna do Programa de Pós Graduação - Mestrado em História, Ensino e Narrativas da Universidade Estadual do Maranhão. Professora da rede Estadual de Educação do Maranhão e do Programa de Formação de Professores Darcy Ribeiro - UEMA.

2 Aluna do Programa de Pós Graduação - Mestrado em História, Ensino e Narrativas da Universidade Estadual do Maranhão. Professora da rede Municipal de Educação de São Luís-Ma.

3 Aluna do Programa de Pós Graduação - Mestrado em História, Ensino e Narrativas da Universidade Estadual do Maranhão. Professora do Instituto Federal do Maranhão.
}

Recebido: $\quad$ maio/2015 $\quad$ Aprovado: jul/2015 